\title{
Correction
}

\section{Correction: Alien Plant Monitoring with Ultralight Airborne Imaging Spectroscopy}

\section{The PLOS ONE Staff}

There is an error in Figure 5, "Carpobrotus aff. edulis detection." Please see the corrected Figure 5 here.

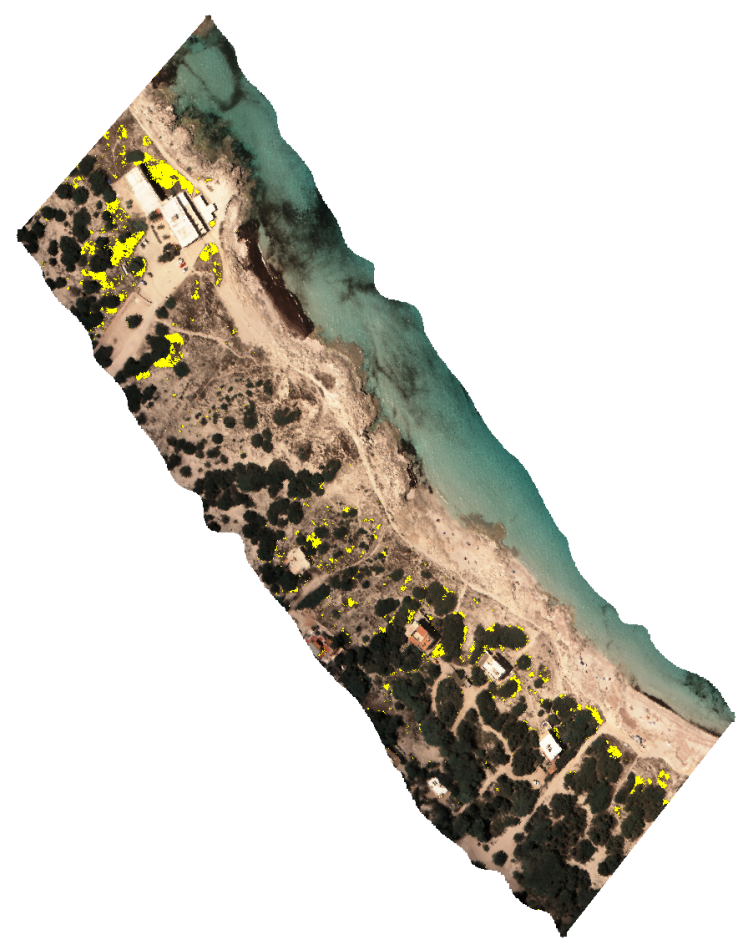

Figure 5. Carpobrotus aff. edulis detection. Classified image showing detection of $C$. aff. edulis highlighted in yellow (Formentera, Balearic Islands, $\left.38^{\circ} 43^{\prime} 52^{\prime \prime} \mathrm{N}, 1^{\circ} 26^{\prime} 50^{\prime \prime} \mathrm{E}\right)$. True colour view of a hyperspectral image by the authors.

doi:10.1371/journal.pone.0102381.g005

\section{Reference}

1. Calviño-Cancela M, Méndez-Rial R, Reguera-Salgado J, Martín-Herrero J (2014) Alien Plant Monitoring with Ultralight Airborne Imaging Spectroscopy. PLoS ONE 9(7): e102381. doi:10.1371/journal.pone.0102381
Citation: The PLOS ONE Staff (2014) Correction: Alien Plant Monitoring with Ultralight Airborne Imaging Spectroscopy. PLoS ONE 9(10): e112031. doi:10.1371/ journal.pone.0112031

\section{Published October 22, 2014}

Copyright: $\odot 2014$ The PLOS ONE Staff. This is an open-access article distributed under the terms of the Creative Commons Attribution License, which permits unrestricted use, distribution, and reproduction in any medium, provided the original author and source are credited. 